\title{
El papel de la experiencia residencial en la elección de entorno. Trayectorias residenciales de centralización y suburbanización
}

\author{
José Manuel Torrado \\ Universidad de Granada. Instituto de Desarrollo Regional \\ josetr@ugr.es \\ Ricardo Duque Calvache \\ Universidad de Granada. Departamento de Sociología \\ ricardoduque@ugr.es

\section{Nayla Fuster} \\ Universidad de Granada. Instituto de Desarrollo Regional \\ naylafuster@ugr.es
}

Recepción: 03-06-2020

Aceptación: 19-11-2020

Publicación: 20-01-2021

\section{Resumen}

La importancia de la experiencia residencial de los sujetos en sus decisiones de movilidad es un hecho reconocido, sin embargo, apenas existen estudios al respecto que traten de cuantificar el efecto de dicho bagaje residencial, y aún menos que traten de analizar cómo puede modular las decisiones de movilidad. En el presente trabajo respondemos precisamente a estas dos cuestiones: ¿cómo influye la experiencia residencial previa de los sujetos con los distintos entornos en la elección por los mismos? y, lo que es más relevante, ¿existen diferencias en los determinantes individuales de elección de entorno residencial según dicha experiencia previa? Para ello, se analizan los determinantes de la centralización y la suburbanización en las áreas metropolitanas españolas a partir de modelos logísticos con los datos del último censo disponible. Se confirma que el hecho de tener experiencia previa en los distintos entornos es un factor relevante para moverse hacia los mismos, pero no solo eso, sino que además los determinantes de dichas elecciones varían sustancialmente según se trate de movimientos de ida o vuelta, lo que apunta a que probablemente tengan explicaciones sustancialmente diferentes.

Palabras clave: experiencia residencial; elección residencial; movilidad residencial; áreas metropolitanas; retorno urbano; centralización; suburbanización 
Abstract. Residential experience and residential location choice. An analysis of centralization and suburbanization residential trajectories

The importance of residential experiences in mobility decisions is a well-known fact. However, there are fewer studies quantifying the effect of this residential background, and even less analyzing how it modulates mobility decisions. In this paper we answer two questions: how does previous residential experience with different environments influence residential location choice? And more important, are there differences in the individual triggers of choice according to such previous experience? To address these issues, the determinants of centralization and suburbanization in Spanish metropolitan areas are studied using logistic regression models on data from the last available census (2011). It is confirmed that previous experience in the different environments is a relevant factor to move towards them. Furthermore, mobility triggers vary substantially depending on previous residential experience with the environment, pointing out that first-time arrivals and return moves probably have different explanations.

Keywords: residential experience; residential location choice; residential mobility; metropolitan areas; back-to-the-city; centralization; suburbanization
Sumario
1. Introducción
4. Resultados
2. La elección de entorno residencial.
5. Conclusiones
Estado de la cuestión
Referencias bibliográficas
3. Fuente, ámbito y metodología

\section{Introducción}

Los entornos residenciales son un componente fundamental para entender los procesos de movilidad y elección residencial de individuos y hogares (Deurloo et al., 1990; Feijten et al., 2008; Mulder y Hooimeijer, 1999). Dentro de la oferta disponible en las actuales ciudades metropolitanas, podemos diferenciar dos tipos generales de entornos: las ciudades centrales o cabeceras metropolitanas, y las coronas o zonas suburbanas, ambas con unas características residenciales, funcionales y sociales (Gober y Behr, 1982; Torrado, 2020) que ofrecen diferentes tipos de oportunidades y constricciones para el desarrollo de las trayectorias vitales y los estilos de vida de los sujetos (Pisman et al., 2011; Rossi, 1955). Por un lado, las cabeceras metropolitanas suelen identificarse con entornos poblacionalmente saturados y densos, que concentran la mayoría de empleos del área metropolitana, así como los principales centros comerciales, educativos, sanitarios y administrativos. En términos residenciales, suele predominar la vivienda en altura, de dimensiones más o menos pequeñas y con un parque de vivienda generalmente antiguo y muy cotizado, sometido a procesos cada vez más acuciantes de gentrificación (Atkinson y Bridge, 2005). Por otro lado, las coronas metropolitanas suelen ser identificadas con zonas residenciales donde dominan las viviendas unifamiliares, de grandes dimensio- 
nes y de construcción relativamente reciente, con amplias zonas verdes y una escasa concentración de funciones que las transforman en zonas propicias para el desarrollo de proyectos de vida familiares alejados del bullicio y los peligros de la ciudad ${ }^{1}$.

Estas diferencias globales constatadas en la oferta residencial metropolitana han hecho que, desde los primeros estudios sobre movilidad residencial (Rossi, 1955), comenzaran a analizarse de manera separada las elecciones residenciales por coronas y cabeceras o, dicho de otro modo, los movimientos de suburbanización y centralización. Respecto a los primeros, la literatura los suele identificar con cambios en los cursos vitales asociados al nacimiento de los hijos y la formación de familia, movimientos caracterizados por un distanciamiento de las zonas centrales, en busca de viviendas amplias, en propiedad y situadas en entornos poco densos y tranquilos que suelen asociarse al llamado estilo de vida suburbano. En cuanto a los segundos, suelen vincularse a cambios vitales o bien previos, o bien posteriores a la formación de familia, de sujetos que buscan la centralidad y la proximidad a las funciones urbanas y las redes de apoyo, asociados a unos estilos de vida más urbanos en los que la localización de la vivienda adquiere un valor en sí mismo. Si bien existen multitud de matices, según la diversidad de contextos locales, la mayoría de literatura previa sobre la cuestión (Duque-Calvache, 2015; Frey, 1985; Frey y Kobrin, 1982; López-Gay y Recaño, 2008; Marois y Bélanger, 2013; Pisman et al., 2011; Torrado, 2018; Turcotte y Vézina, 2010) suele apuntar en la línea de lo mencionado, con la vinculación de suburbanización y centralización a acontecimientos de los cursos vitales, grupos sociales y estilos de vida generalmente complementarios.

Sin embargo, hasta el momento poco se sabe del papel que tiene la experiencia residencial previa de los sujetos en la elección de entorno residencial. La experiencia para con los distintos entornos es una variable que se ha demostrado clave en la explicación de los movimientos residenciales y migratorios de retorno (Cassarino, 2004; Feijten et al., 2008). El lugar de origen suele coincidir en gran medida con el lugar donde se concentran la mayoría de redes familiares, un determinante fundamental de la movilidad (Mulder y Cooke, 2009). Además, el hecho de haber pasado un tiempo significativo de la vida en un entorno posibilita que los individuos configuren allí redes sociales de apoyo más amplias, así como que acumulen recursos materiales, como puede ser una vivienda, o incluso inmateriales, como es el conocimiento de

1. Si bien es cierto que, en términos de promedio, las cabeceras y coronas metropolitanas españolas responden a estas diferencias globales, no es menos cierto que son entornos muy heterogéneos internamente (Otero-Enríquez, 2017). No obstante, en el presente trabajo optamos por esta diferenciación simple por dos razones: primero, porque se constata en términos generales para el universo metropolitano español (Torrado, 2020); segundo, porque se adecua a nuestro objeto, que no es otro que conocer el efecto global de la experiencia residencial en los movimientos de centralización y suburbanización, en toda la ciudad y en todas las ciudades. Una opción también tomada por otros estudios que han tratado de abordar la cuestión en otros contextos nacionales (Blaauboer, 2011; Feijten et al., 2008). 
las oportunidades laborales y residenciales que el entorno ofrece. Más allá de esto, algunas investigaciones previas (Feldman, 1990; 1996) demuestran que la experiencia residencial con los distintos entornos, especialmente durante la etapa de socialización primaria (Blaauboer, 2011), es clave en la configuración de los imaginarios urbanos, los cuales marcan, prácticamente de por vida, las preferencias residenciales de los sujetos, lo que hace que, tarde o temprano, tiendan a regresar a aquellos entornos con los que tienen una mayor vinculación afectiva.

En el caso concreto de la centralización y la suburbanización, desde los estudios de Rossi (1955), la literatura tiende a identificar la suburbanización como un movimiento de ida de sujetos urbanitas que buscan la consecución de proyectos de vida familiares (Michielin y Mulder, 2008), frente a una centralización algo más diversa, vinculada a la llegada de hijos de suburbanitas en las primeras etapas de sus trayectorias educativas y laborales (Marois y Bélanger, 2013), pero especialmente al retorno de antiguos residentes tras el final, o fracaso, de su proyecto de vida en las coronas (Shin, 2012). No obstante, pese a estos indicios, a día de hoy son muy pocos los estudios que han tratado de analizar el efecto de la experiencia residencial en la elección de cabeceras y coronas (Blaauboer, 2011; Feijten et al., 2008), y de hecho ninguno hasta el momento que analice cómo los determinantes individuales que llevan a la elección de unos y otros pueden variar según el bagaje residencial previo.

En el presente trabajo, se responde precisamente a estas dos cuestiones: ¿cómo la experiencia residencial previa de los sujetos con los distintos entornos influye en la elección por los mismos? y, lo que es más relevante, ¿existen diferencias en los determinantes individuales de elección de entorno residencial según dicha experiencia previa? Nos marcamos dos objetivos fundamentales a fin de responder a dichas cuestiones:

1. Conocer la importancia de la experiencia residencial previa de los sujetos en la elección de entorno residencial, concretamente en la elección de cabeceras (centralización) y coronas (suburbanización).

2. Analizar las diferencias en los determinantes de los movimientos de centralización y suburbanización según la experiencia residencial previa de los sujetos, es decir, según sean movimientos de ida o vuelta.

Para alcanzar estos objetivos se dan varios pasos sucesivos. En primer lugar, se propone una revisión de la literatura sobre elección de entorno residencial dividiéndola en dos ejes o momentos teóricos diferentes, según la dimensión de los entornos considerada en el análisis de la elección: un primer momento que hemos llamado «enfoque del ajuste funcional», el cual revela relaciones interesantes entre los cursos vitales, la posición social y los estilos de vida en la elección de entorno; y un segundo momento, en el cual se enmarca este trabajo, en el que comienza a considerarse la importancia y las modulaciones que introduce la consideración del bagaje residencial previo de los actores en 
sus elecciones residenciales. En un segundo punto, se reflexiona sobre la fuente empleada —el Censo de Población y Vivienda 2011—, se muestra el ámbito de estudio - las áreas metropolitanas españolas-y se detalla la estrategia metodológica desarrollada. En el apartado de resultados, se muestra el análisis de la elección residencial por cabeceras (centralización) y coronas (suburbanización), en dos fases secuenciales. En primer lugar, se considera la experiencia residencial como un factor explicativo de la elección de entorno ponderando su importancia y efecto; en segundo lugar, se analizan las diferencias existentes en los determinantes de suburbanización y centralización según sean realizados por sujetos con experiencia residencial previa en los entornos hacia los que se mueven (vuelta o retorno) o por sujetos que van hacia ellos por primera vez (ida). Por último, se reflexiona sobre las consecuencias e implicaciones de este estudio para la investigación futura.

\section{La elección de entorno residencial. Estado de la cuestión}

De manera simultánea a la decisión de moverse, individuos y hogares deben sopesar otra compleja decisión: ¿hacia dónde moverse? (Dejong y Gardner, 1981). Según Mulder y Hooimeijer (1999), los distintos entornos hacia los que las personas deciden moverse tienen dos dimensiones fundamentales, una objetiva (sites) y otra subjetiva (situation), que los individuos deben considerar a la hora de realizar su elección residencial. La dimensión objetiva se refiere a las características físicas y funcionales del entorno, tales como la presencia de determinados servicios, instalaciones, tipos de vivienda..., pero también a las características sociales de los mismos, mientras que la dimensión subjetiva tiene que ver con las posibilidades particulares que ofrece la localización para articular los espacios en que se desenvuelve la vida cotidiana (trabajo, ocio, familia, escuela, amigos, etcétera). Son varios los autores que, en distintos momentos, enfatizaron sobre la importancia del componente subjetivo en la movilidad residencial, que va más allá de la mera situación relativa respecto a los espacios de vida inicialmente planteada, ya que expande esta dimensión subjetiva a los imaginarios sobre los espacios y vínculos afectivos ligados a experiencias de los individuos (Bachelard, 1957; Feijten et al., 2008; Susino, 2003), así como a los capitales localizados en los distintos entornos (Da Vanzo, 1981).

No obstante, y pese a que el trabajo seminal de Mulder y Hooimeijer (1999) ya identificaba estas dos dimensiones asociadas a los entornos residenciales, los trabajos sobre elección de entorno residencial no siempre las han considerado en su totalidad, y se han podido identificar dos momentos en la literatura: un primer momento caracterizado por trabajos más centrados en conocer qué factores individuales llevan a elegir determinados entornos residenciales, en los cuales se da más peso a las características objetivas de los entornos (sites); y un segundo momento en el que comienza a tenerse en consideración el papel de la dimensión subjetiva de los entornos (situation), con el análisis del efecto de la experiencia residencial en la elección. 


\subsection{Cursos vitales, posición social y estilos de vida en la elección de entorno residencial}

La elección residencial por cabeceras y coronas fue abordada desde muy temprano por la literatura sobre comportamiento residencial, pues ya encontramos las primeras aportaciones en el clásico trabajo de Rossi (1955). El autor establece que la suburbanización (elección por las coronas) corresponde principalmente a las primeras etapas del ciclo vital, es decir, es una forma de movilidad de ajuste o anticipación al nacimiento de los hijos (Michielin y Mulder, 2008), mientras que la centralización (la elección por las cabeceras) se vincula a cambios en el ciclo vital posteriores a la formación de familia, relacionados con la disolución del hogar o la entrada en la etapa de nido vacío (Shin, 2012). Se trata de una visión de la elección residencial un tanto mecánica, en la medida en que la explicación que subyace es que cabeceras y coronas son entornos diferenciados que, por sus características objetivas, son más aptos para unas fases del ciclo de vida que para otras.

Este trabajo de Rossi inaugura el primer momento en los estudios sobre elección del entorno residencial, un grupo de trabajos centrados en tratar de explicar quién elige un entorno u otro o, mejor dicho, qué determinantes individuales llevan a optar por cabeceras o coronas. Según esta explicación, los individuos deciden relocalizar su residencia en el entorno que posea las características objetivas (servicios y funciones, tipos de vivienda y composición social) que mejor permitan realizar sus preferencias, las cuales se configuran a partir de sus características personales. Hemos dado en llamar a esta explicación de la elección residencial «enfoque del ajuste funcional», debido a que explica la elección residencial como una búsqueda de equilibrio entre las preferencias emergentes y las características objetivas de los espacios.

Según esta explicación, los individuos optarán por moverse hacia las cabeceras o coronas según tres factores fundamentales que configuran sus preferencias residenciales: los eventos de los cursos vitales que les ocurran; su posición social, que en gran medida es el mejor indicador para operacionalizar lo que Mulder y Hooimeijer (1999) llamaban recursos y restricciones; y sus estilos de vida, una dimensión que se refiere a las actitudes y prácticas relacionadas con la familia, la interacción social y el uso del espacio. Estas tres características personales hacen que emerjan en los individuos diferentes preferencias residenciales que los llevan a buscar el entorno que por sus características objetivas (sites) mejor se ajuste a las mismas. En la figura 1 esquematizamos la explicación de la elección de entorno residencial según este enfoque.

Los trabajos enmarcados bajo esta explicación han conseguido establecer relaciones bastante claras entre estos tres aspectos de las características personales y la elección por cabeceras y coronas.

En términos de acontecimientos de los cursos vitales, estos trabajos señalan que la elección por las cabeceras (centralización) suele vincularse a individuos que se encuentran, o bien en etapas previas, o bien en etapas posteriores a la formación de familia (Frey y Kobrin, 1982; López-Gay y Recaño, 2008; 
Figura 1. Explicación de la elección de entorno residencial según el «enfoque del ajuste funcional»

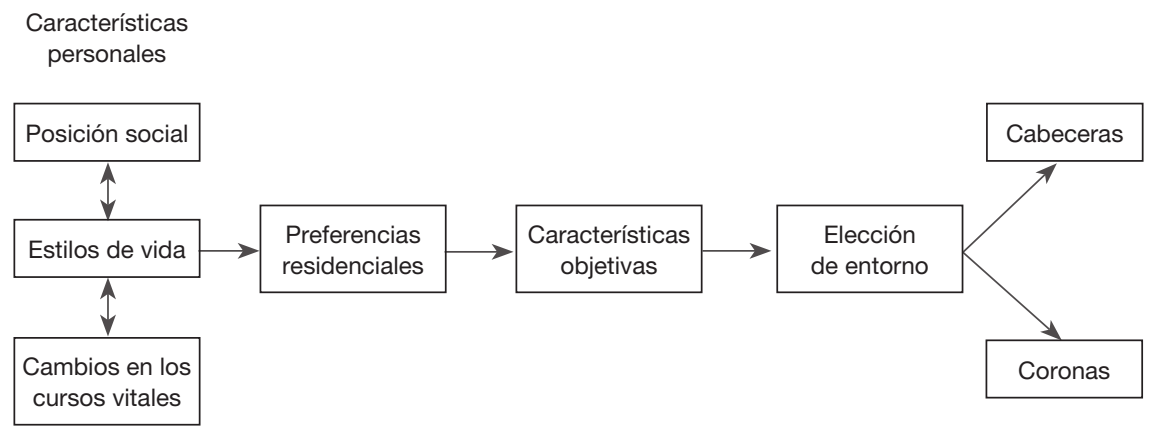

Fuente: elaboración propia desarrollando la propuesta de Mulder y Hooimeijer (1999).

Shin, 2012). Son jóvenes que se mueven hacia las ciudades por el inicio de su etapa formativa (Marois y Bélanger, 2013) y suelen vivir en hogares no familiares (Buzar et al., 2007), otros que buscan consolidar sus carreras profesionales y aprovechar las oportunidades que ofrecen los centros urbanos (Fielding, 1992), parejas donde los dos miembros trabajan y necesitan proximidad a los espacios de trabajo para conciliar y repartir las tareas reproductivas (Bailey et al., 2004), personas mayores que se divorcian y acuden a la ciudad en busca de servicios, redes sociales y viviendas adecuadas a las condiciones sobrevenidas (Feijten y Ham, 2007), pero también, aunque de manera más marginal, familias completas que optan por residir en las cabeceras atraídas por las funciones y los servicios que estas concentran (Booi y Boterman, 2020; Boterman et al., 2010). En cambio, la elección por las coronas suburbanas suele vincularse a acontecimientos de los cursos vitales relacionados con el nacimiento (o la expectativa de nacimiento) de los hijos y la formación de una familia nuclear, dadas las mejores condiciones de las zonas suburbanas para la crianza de los hijos: ambientes más saludables, tranquilidad, homogeneidad social, viviendas más espaciosas, etcétera (Alberich, 2010; Lupi y Musterd, 2016; Miller, 1995; Shin, 2012; Susino y Duque-Calvache, 2012).

Respecto a la posición social, los estudios arrojan resultados contradictorios según los contextos urbanos en los que se hayan realizado. Así, los trabajos norteamericanos más clásicos solían vincular la elección por las cabeceras a personas de bajos ingresos (Nelson y Edwards, 1993), frente a unas coronas suburbanas consolidadas como la elección de las clases medias (Ullán de la Rosa, 2014). Justo es el caso contrario de los estudios europeos, los cuales muestran como la elección de las cabeceras es la opción favorita de las clases medias, frente a unas coronas metropolitanas pobladas en mayor medida por sectores populares (Castells, 1976), aunque también mixtas, con importantes zonas de clase media (Susino, 2003). No obstante, en las últimas décadas parece que, incluso en el caso norteamericano (Atkinson y Bridge, 2005; Ley, 1996), la 
elección por las cabeceras se está erigiendo como la opción favorita de las clases medias (López-Gay y Recaño, 2008), algo muy asociado a los procesos de gentrificación (Duque-Calvache, 2016), frente a unas coronas metropolitanas que, cada vez más, alojan a los sectores sociales populares (Cooke y Denton, 2015).

Por último, en cuanto a los estilos de vida, la elección por las cabeceras se ha vinculado convencionalmente a individuos con estilos de vida urbanos más individualistas (Schnell y Gracier, 1993); individuos centrados en el trabajo que relegan a un segundo plano las trayectorias familiares (Mahmud et al., 2012), que buscan la proximidad a los lugares de trabajo, pero también a los servicios y a los lugares de encuentro y ocio, con ideologías principalmente progresistas (Caufield, 1993; Lees et al., 2013), para los cuales la centralidad se torna en un valor en sí mismo, ya que supeditan las características de la vivienda a la localización (Cosacov et al., 2018) y configuran una parte relevante de su identidad a través de su posicionamiento dentro de un entorno central (Pablos y Sánchez-Tovar, 2003). En cambio, la elección por las coronas es más propia de individuos con unos estilos de vida basados en el ideal de familia nuclear (Miller, 1995), que buscan tranquilidad, viviendas amplias (Pisman et al., 2011), homogeneidad social (Mieszkowski y Mills, 1993) y la posibilidad de articular los espacios de vida de manera selectiva, donde el distanciamiento adquiere un valor en sí mismo (Alberich, 2010).

Si bien este «enfoque del ajuste funcional» ha servido de marco para que muchos trabajos previos establezcan relaciones entre las características personales de los individuos y la elección de entornos residenciales, esta explicación se muestra insuficiente. Aunque es evidente que las características objetivas de los entornos influyen en la elección (Bayoh et al., 2006), el proceso de decisión es bastante más complejo, ya que la valoración que los individuos hacen de las características de un entorno concreto puede variar sustancialmente según su experiencia residencial (Blaauboer, 2010; Feijten et al., 2008), es decir, según los imaginarios, vinculaciones afectivas y capitales que los individuos tienen en los distintos entornos.

\subsection{La importancia de la experiencia residencial}

La consideración de estas limitaciones ha hecho que la explicación se enriquezca en los últimos años con algunas aportaciones que han profundizado en el papel que tiene en el proceso de elección residencial el componente subjetivo (Æro, 2006; Blaauboer, 2011; Clapham, 2002; Feijten et al., 2008). Esta dimensión subjetiva de los entornos comprende dos componentes íntimamente relacionados que los individuos tienen en consideración a la hora de realizar sus elecciones residenciales: los imaginarios sobre lo urbano y lo suburbano, y los distintos recursos o capitales localizados en el espacio.

Los imaginarios atañen a cómo los entornos son percibidos por los sujetos, es decir, a las distintas valoraciones, identificaciones y emociones que tienen respecto a estos. Si bien parte de estos imaginarios sobre las zonas de la ciudad son compartidos y están marcados por la propia historia urbana del espacio 
(Aragonés y Amérigo, 1987; Conde, 1999), no se limitan a la percepción generalizada en un momento dado, sino que tienen relación con las vivencias de los propios individuos (Bachelard, 1957). A lo largo del proceso de experiencia residencial, los individuos van cargando los distintos espacios de recuerdos y vivencias pasadas que los dotan de significados, de modo que se configuran mentalmente como entornos subjetivos tanto en el terreno simbólico como en el afectivo, lo que hace que los sujetos desarrollen eso que comúnmente llamamos arraigo (Clark et al., 2015), pero también desarraigo (dependiendo del tipo de experiencias vividas en los espacios).

En esta línea, en una investigación cualitativa sobre decisiones residenciales, Susino (2003) observó que, aunque las primeras explicaciones sobre las decisiones residenciales aludían a los componentes objetivos, conforme avanzaban las entrevistas emergía un trasfondo motivacional más complejo. Un componente subjetivo donde las vivencias y recuerdos, incluso los de la infancia, cobraban un papel importante para explicar las trayectorias residenciales. Así, en las disposiciones que poseen los individuos en relación con la vivienda y los entornos residenciales, y que configuran sus imaginarios sobre la ciudad y sus pautas de movilidad respecto a los distintos entornos (Ærø, 2006), parecen tener gran importancia las experiencias vividas durante la socialización primaria (Blaauboer, 2011), en las cuales los individuos desarrollan sus identidades más fuertes e internalizadas (Martín-Criado, 2013). Aquí también intervienen otras informaciones adquiridas a través de diversos agentes de socialización, como los medios de comunicación, el grupo de iguales o la familia, que hacen que los individuos adquieran ideas preconcebidas sobre las distintas tipologías de vivienda y entornos residenciales, aunque ni siquiera hayan tenido la más mínima experiencia directa respecto a las mismas (Feldman, 1990; 1996; Kintrea, 2007).

Al tiempo, en el proceso socializador, los individuos van dotándose de distintos capitales o recursos sociales, económicos y culturales (Blaauboer, 2011) que, en cierta medida, orientan su elección residencial. Respecto a los recursos sociales, nos referimos especialmente al capital social de los individuos, a las distintas redes de contactos que van construyendo a lo largo de sus vidas en el espacio urbano. A este respecto, estudios previos han demostrado la importancia de las redes familiares en la localización de la residencia (Mulder y Cooke, 2009), pero también de las redes de amistad y de la calidad e intensidad de las relaciones vecinales (Dawkins, 2006; Viry, 2012). En cuanto a los recursos económicos, nos referimos especialmente a la posesión de una vivienda, algo que, sin duda, genera una condición de posibilidad para la elección de entorno nada desdeñable. En términos de capital cultural, Blaauboer (2011) habla del conocimiento que tienen las personas sobre los entornos, es decir, la cantidad y la calidad de información que manejan sobre el mercado de vivienda y trabajo en las distintas zonas de la ciudad. Este conocimiento es muy útil de cara a barajar distintas oportunidades laborales, o para el alquiler o la adquisición de una vivienda en una localización y unas condiciones que se ajusten en mayor grado a las preferencias. 
Figura 2. La importancia de la experiencia residencial en la elección de entorno

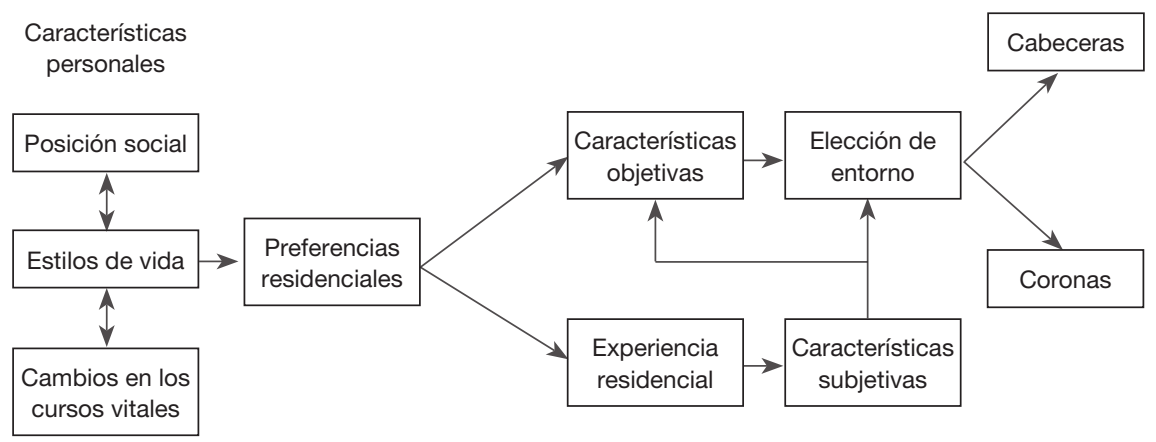

Fuente: elaboración propia desarrollando las propuestas de Mulder y Hooimeijer (1999) y Feijten et al. (2008).

De esta manera, la consideración de los entornos subjetivos supone una explicación más compleja del proceso de elección del entorno residencial. Si el «enfoque del ajuste funcional» reducía la elección residencial a una decisión racional en la que los individuos eligen los entornos que objetivamente mejor se adaptan a sus preferencias, esta explicación más compleja introduce la dimensión subjetiva de los entornos, construida a lo largo de la trayectoria residencial de los individuos, y que hace que el proceso de elección de entorno se guie, además de por sus características objetivas, por la valoración subjetiva y los recursos localizados que poseen los individuos. Esta dimensión subjetiva, lejos de ser una mera adición al esquema objetivista de elección residencial, puede incluso condicionar de qué manera son valoradas y gestionadas por los individuos las limitaciones y oportunidades impuestas por las características objetivas de los entornos. En la figura 2, puede observarse cómo queda el esquema conceptual para la explicación de la elección de entorno residencial al introducir la dimensión subjetiva.

Los estudios más recientes que han considerado este esquema más complejo han establecido relaciones bastante claras entre la experiencia residencial y la elección de cabeceras y coronas. El lugar en el que transcurre la socialización primaria (Blaauboer, 2011) e incluso el lugar de nacimiento (Feijten et al., 2008) son relevantes a la hora de elegir entorno residencial, de manera que los individuos suelen pasar la mayor parte de sus vidas en los mismos entornos (Stovel y Bolan, 2004) o retornar a ellos en caso de haberse mudado.

\section{Fuente, ámbito y metodología}

La fuente empleada es el Censo de Población y Vivienda 2011, para el cual se cuenta con una explotación propia que contempla la delimitación de las 44 áreas metropolitanas españolas propuesta por Feria y Martínez (2016). Contar con esta delimitación permite territorializar los datos individualizados del censo 
Figura 2. Delimitación de las áreas metropolitanas españolas en 2011 divididas según sus entornos residenciales principales

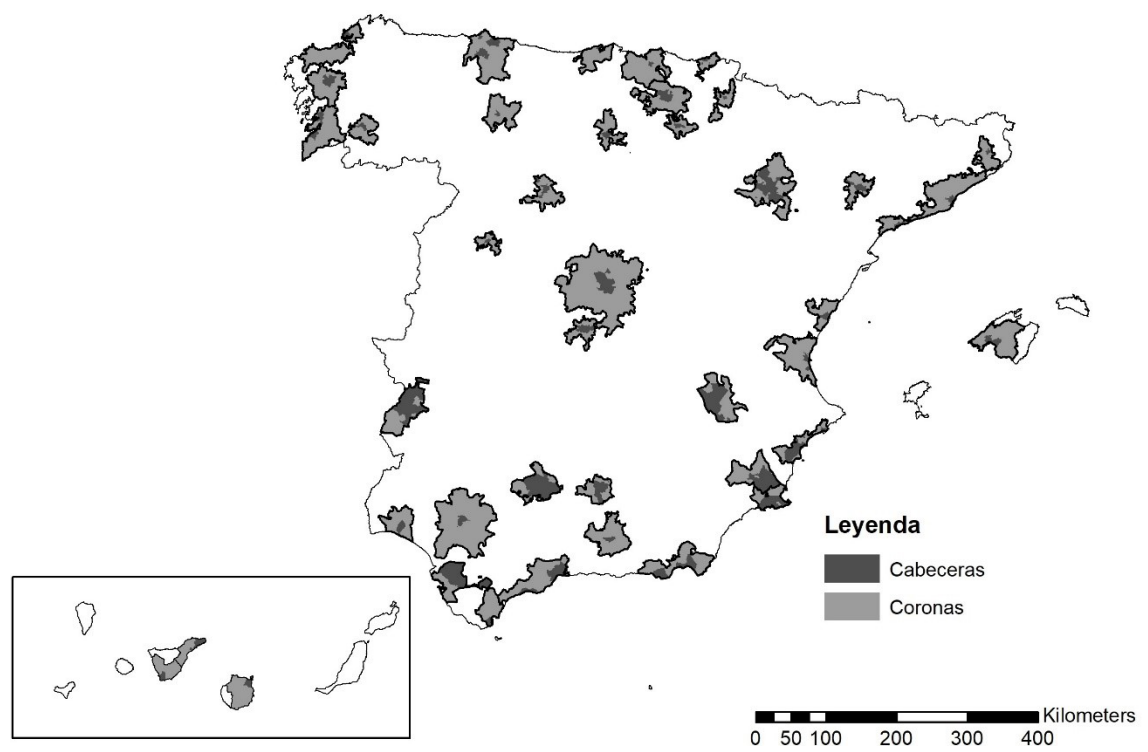

Fuente: elaboración propia a partir de la delimitación de Feria y Martínez (2016).

según el tipo de entorno de residencia (ver figura 3), lo que posibilita tanto diferenciar en sentido estricto los movimientos residenciales de centralización y suburbanización, excluyendo las migraciones, como identificar el tipo de entorno en el que los individuos nacieron, algo central para aproximarse a la experiencia residencial a través del censo.

Entre las principales ventajas de la fuente censal, se encuentra el hecho de tener datos individualizados representativos de la totalidad del universo metropolitano español y, especialmente, contener una amplia variedad de variables individuales que sirven para operacionalizar los distintos factores individuales de la elección residencial. Entre estas últimas, el censo comprende variables indicativas de los cursos vitales, tales como la edad, la forma de convivencia o el estado civil; variables referentes a la posición social, como son el nivel de estudios y la condición sociolaboral, y variables que sirven para aproximarse a los estilos de vida, como el número de tareas domésticas que el individuo realiza o el lugar de trabajo o estudios. ${ }^{2}$ Pero, además, el censo cuenta con una variable central para este estudio y que no ha sido suficientemente explotada

2. Somos conscientes de lo limitado de estas variables, pero es la única aproximación posible a esta dimensión. La primera trata de aproximarse al grado de asunción de trabajo doméstico por parte del individuo, mientras que la segunda sirve para conocer el grado de concentración o dispersión de su espacio del habitar. 
en el análisis de la movilidad residencial: el lugar de nacimiento. Si bien resulta evidente que es una aproximación ciertamente imprecisa a los aspectos subjetivos, investigaciones precedentes han demostrado que el entorno de nacimiento suele coincidir en gran medida con el entorno de residencia (Feijten et al., 2008), lo que muestra la importancia que tiene el lugar de nacimiento en la configuración del arraigo, ya que es una variable de uso recurrente en investigaciones similares (Pino-Artacho, 2013; Feijten et al., 2008).

Se emplean dos variables dependientes fundamentales: una para analizar la elección por las cabeceras (centralización) y otra para analizar la elección por las coronas (suburbanización), ambas dicotómicas. La primera (centralización) pone en relación la población que decidió mudarse desde las coronas hacia las cabeceras en el año anterior al censo (valor 1 de la variable) con aquella que permaneció en las coronas (valor 0). La segunda (suburbanización) relaciona aquella población que decidió mudarse desde las cabeceras hacia las coronas el año anterior al censo (valor 1) con la que optó por permanecer en las cabeceras (valor 0 ). Creemos que la construcción de las variables dependientes refleja bien los procesos individuales de elección residencial, en la medida en que contempla las opciones reales que tienen los sujetos. Además, tomar la movilidad en el año anterior al censo ayuda a evitar el sesgo que siempre supone trabajar con una base de datos transversal, lo que hace que la distancia temporal entre el momento en el que transcurrió el movimiento (2010, el año anterior al censo) y el momento censal (2011, en el que se registran las variables individuales) sea mínima, para permitir así aproximarse de manera bastante certera a los determinantes reales de la elección residencial.

En cuanto a la estrategia metodológica, se presenta un análisis en dos pasos sucesivos construyendo en ambos casos modelos de regresión logística binaria, que es la técnica más adecuada dada la naturaleza de las elecciones residenciales a analizar y la operacionalización propuesta para las mismas. De entrada, se aborda el primer objetivo, que, recordemos, es conocer la importancia de la experiencia residencial previa de los sujetos en la elección de entorno residencial. Para ello, se construyen dos modelos por cada elección considerada (centralización y suburbanización). En el primero, se introducen todas las variables independientes referentes a los cursos vitales, la posición social y los estilos de vida. En un segundo paso, se introduce la variable indicativa de la experiencia residencial, el lugar de nacimiento. El objetivo es contrastar la importancia de la experiencia residencial —algo que se realiza observando la magnitud de los cambios que se producen en el criterio de Akaike y en el criterio de información bayesiana (Escobar et al., 2009) — para inmediatamente después analizar la significatividad y el efecto de dicha variable en las dos elecciones consideradas. En segundo lugar, una vez constatada la pertinencia de la variable indicativa de la experiencia residencial en la centralización y la suburbanización, se aborda el segundo objetivo: analizar las diferencias en los determinantes de los movimientos de centralización y suburbanización según sean movimientos de ida o vuelta. Para ello se modeliza por separado cada elección residencial sobre submuestras diferentes, primero, para aquellos que han nacido en el entorno 
hacia el que se mueven (cabecera de la misma área en caso de la centralización; corona de la misma área en caso de la suburbanización), y después para aquellos que no han nacido en dicho entorno. Para poder comparar los determinantes de los movimientos de ida y vuelta, se calculan los efectos marginales medios ${ }^{3}$ (AMEs $\mathrm{dy} / \mathrm{dx}$ ), una medida recomendada para comparar modelos realizados sobre submuestras diferentes (Williams, 2012).

Por último, cabe decir que en la realización de todos los análisis se han eliminado de la muestra a los menores de 16 años por dos razones. La primera es porque no disponen de información en variables indicativas de la posición social (nivel de estudios y condición sociolaboral). Y la segunda es porque en la mayoría de casos la movilidad de este grupo etario no es más que el reflejo de la de sus padres o tutores legales, lo que llevaría a sobrevalorar la presencia de algunas categorías sobre otras (por ejemplo, las parejas con hijos).

\section{Resultados}

\subsection{La importancia de la experiencia residencial en la elección de entorno}

Los modelos construidos (tabla 1) muestran que la experiencia residencial es una variable relevante para la explicación de la elección de entorno. Si bien los incrementos en el pseudo- $\mathrm{R}^{2}$ no son de gran magnitud, las reducciones en el criterio bayesiano (BIC) y en el de Akaike (AIC) son lo suficientemente grandes como para considerar la significatividad de la variable indicativa de la experiencia residencial. Además, la gran significatividad de la mayoría de sus categorías refuerza esta aseveración. No obstante, es cierto que el efecto parece mayor en el caso de la centralización que en el de la suburbanización, así lo reflejan las mayores reducciones en los estadísticos mencionados para el caso de la primera.

En cuanto al efecto y la dirección de la variable indicativa de la experiencia residencial, también se aprecian tendencias interesantes en ambas elecciones que deben ser comentadas.

Con relación a la elección por las cabeceras, es destacable en primer lugar que todas las categorías presenten una propensión negativa a la centralización respecto a los nacidos en las cabeceras (categoría de referencia), lo cual demuestra que la centralización se configura en mayor medida como un movimiento de retorno.

En segundo lugar, cabe decir que, aunque todas las categorías presentan signo negativo, el coeficiente es menor (menos negativo) en el caso de los nacidos en el extranjero, seguidos de aquellos que nacieron en las cabeceras de otras áreas distintas a la de residencia actual. Lo primero se explica por la mayor movilidad general que presentan siempre las categorías de extranjeros.

3. De manera muy simple, podemos decir que los efectos marginales medios indican la probabilidad media que tiene un individuo de unas características determinadas de realizar la elección analizada calculándose sobre el supuesto de que el resto de características son las realmente presentes en cada caso. Para más información sobre los efectos marginales medios, véase Williams (2012); para una explicación detallada en castellano, véase Torrado (2020). 
Tabla 1. Modelos por pasos para la explicación de la centralización y suburbanización

\begin{tabular}{|c|c|c|c|c|c|c|c|c|}
\hline & \multicolumn{4}{|c|}{ Centralización } & \multicolumn{4}{|c|}{ Suburbanización } \\
\hline & \multicolumn{2}{|c|}{ Modelo 1} & \multicolumn{2}{|c|}{ Modelo 2} & \multicolumn{2}{|c|}{ Modelo 1} & \multicolumn{2}{|c|}{ Modelo 2} \\
\hline & B & SE & B & SE & B & SE & B & SE \\
\hline Edad & 0,007 & 0,012 & 0,003 & 0,012 & $-0,076^{\star \star \star}$ & 0,009 & $-0,078^{\star \star \star}$ & 0,009 \\
\hline Edad al cuadrado & $-0,000^{\star \star}$ & 0,000 & $-0,000^{\star \star}$ & 0,000 & $0,000^{\star \star \star}$ & 0,000 & $0,000^{\star \star \star}$ & 0,000 \\
\hline \multicolumn{9}{|l|}{ Sexo (ref. = mujer) } \\
\hline Hombre & $0,191^{\star \star}$ & 0,056 & $0,179^{\star \star}$ & 0,056 & $-0,017$ & 0,040 & $-0,011$ & 0,040 \\
\hline \multicolumn{9}{|l|}{ Estado civil (ref. = casado) } \\
\hline Soltero & $0,406^{\star \star \star}$ & 0,074 & $0,429^{\star \star \star}$ & 0,074 & $0,251^{\star \star \star}$ & 0,070 & $0,293^{\star \star \star}$ & 0,068 \\
\hline Viudo & $0,956^{\star \star \star}$ & 0,135 & $0,951^{\star \star \star}$ & 0,136 & $0,716^{\star \star \star}$ & 0,113 & $0,724^{\star \star \star}$ & 0,113 \\
\hline Separado o divorciado & $0,935^{\star \star \star}$ & 0,085 & $0,937^{\star \star \star}$ & 0,085 & $0,866^{\star \star \star}$ & 0,072 & $0,874^{\star * *}$ & 0,071 \\
\hline \multicolumn{9}{|l|}{ Forma de convivencia (ref. = unipersonal) } \\
\hline No familiar & $1,379^{\star \star \star}$ & 0,123 & $1,356^{\star \star \star}$ & 0,123 & $0,407^{\star \star}$ & 0,123 & $0,340^{\star \star}$ & 0,123 \\
\hline Monop. hijos menores & $-0,740^{\star \star \star}$ & 0,137 & $-0,749^{\star \star \star}$ & 0,137 & $-1,026^{\star \star \star}$ & 0,115 & $-1,036^{* * *}$ & 0,115 \\
\hline Monop. hijos mayores & $-0,175$ & 0,133 & $-0,180$ & 0,134 & $-0,747^{\star \star \star}$ & 0,119 & $-0,738^{\star \star \star}$ & 0,119 \\
\hline Pareja sin hijos & $0,574^{\star \star \star}$ & 0,092 & $0,569^{\star \star \star}$ & 0,092 & $0,854^{\star \star *}$ & 0,071 & $0,850^{\text {*** }}$ & 0,071 \\
\hline Pareja con hijos menores & $-0,829^{\star \star \star}$ & 0,100 & $-0,840^{\star \star \star}$ & 0,100 & $-0,404^{\star \star \star}$ & 0,078 & $-0,429^{\star \star *}$ & 0,078 \\
\hline Pareja con hijos mayores & $-0,969^{\star \star \star}$ & 0,135 & $-0,982^{\star \star \star}$ & 0,135 & $-0,804^{\star \star \star}$ & 0,112 & $-0,796^{\star * *}$ & 0,112 \\
\hline Otras familias & $0,389^{\star \star \star}$ & 0,091 & $0,352^{\star \star \star}$ & 0,092 & $0,363^{\star \star \star}$ & 0,072 & $0,262^{\star \star \star}$ & 0,072 \\
\hline \multicolumn{9}{|l|}{ Nivel de estudios (ref. = primarios o menos) } \\
\hline Secundarios & 0,004 & 0,093 & $-0,010$ & 0,093 & 0,016 & 0,083 & 0,034 & 0,082 \\
\hline Bachiller o FP & $0,281^{\star \star}$ & 0,092 & $0,223^{*}$ & 0,092 & $-0,023$ & 0,080 & $-0,027$ & 0,079 \\
\hline Superiores & $0,907^{\star \star \star}$ & 0,098 & $0,830^{\star \star \star}$ & 0,097 & $-0,138$ & 0,084 & $-0,133$ & 0,084 \\
\hline \multicolumn{9}{|l|}{ Condición sociolaboral (ref. = administrativos) } \\
\hline Profesionales & 0,084 & 0,082 & 0,096 & 0,082 & $-0,102$ & 0,058 & $-0,086$ & 0,058 \\
\hline Servicios & 0,064 & 0,091 & 0,056 & 0,090 & $0,139^{\star}$ & 0,065 & 0,077 & 0,066 \\
\hline Operarios & $-0,537^{\star \star \star}$ & 0,101 & $-0,525^{\star \star \star}$ & 0,101 & $-0,096$ & 0,075 & $-0,141$ & 0,075 \\
\hline Empresarios & $-0,399^{\star *}$ & 0,118 & $-0,379^{\star \star}$ & 0,118 & $0,208^{*}$ & 0,093 & 0,177 & 0,093 \\
\hline Otros ocupados & $-0,396^{\star}$ & 0,174 & $-0,396^{*}$ & 0,174 & $-0,584^{\star \star \star}$ & 0,137 & $-0,630^{\star * *}$ & 0,137 \\
\hline Parados & $-0,215^{\star}$ & 0,100 & $-0,211^{*}$ & 0,100 & $-0,500^{\star \star \star}$ & 0,077 & $-0,526^{\star * *}$ & 0,077 \\
\hline Inactivos & $-0,393$ & 0,207 & $-0,372$ & 0,207 & $-0,067$ & 0,162 & $-0,080$ & 0,162 \\
\hline$\underline{N}{ }^{0}{ }^{0}$ de tareas domésticas que realiza & $-0,136^{\star \star \star}$ & 0,035 & $-0,132^{\star \star \star}$ & 0,035 & $0,088^{\star \star \star}$ & 0,025 & $0,097^{\star \star \star}$ & 0,025 \\
\hline \multicolumn{9}{|c|}{ Lugar de trabajo o estudios (ref. = mismo municipio) } \\
\hline Otro municipio del área & $-1,204^{\star \star \star}$ & 0,075 & $-1,247^{\star \star \star}$ & 0,076 & $3,101^{\star \star \star}$ & 0,073 & $3,091^{\star * \star}$ & 0,073 \\
\hline Fuera del área & $-1,066^{\star \star \star}$ & 0,140 & $-1,048^{\star \star \star}$ & 0,140 & $1,190^{\star \star \star}$ & 0,129 & $1,206^{\star \star \star}$ & 0,129 \\
\hline Varios municipios & $-0,648^{\star \star \star}$ & 0,150 & $-0,675^{\star \star \star}$ & 0,150 & $1,563^{\star \star \star}$ & 0,109 & $1,563^{\star \star \star}$ & 0,109 \\
\hline Mismo domicilio & $-0,629^{\star \star \star}$ & 0,105 & $-0,644^{\star \star \star}$ & 0,105 & $1,440^{\star \star *}$ & 0,096 & $1,440^{\star \star \star}$ & 0,096 \\
\hline No estudia ni trabaja & $-0,555^{\star \star \star}$ & 0,064 & $-0,579^{\star \star \star}$ & 0,064 & $1,484^{\star \star *}$ & 0,081 & $1,467^{\star \star \star}$ & 0,082 \\
\hline \multicolumn{9}{|c|}{ Tenencia de la vivienda principal (ref. = propiedad hipotecada) } \\
\hline Propiedad totalmente pagada por compra & $-0,285^{\star \star}$ & 0,084 & $-0,209^{*}$ & 0,085 & $-1,303^{\star \star \star}$ & 0,059 & $-1,275^{\star \star \star}$ & 0,060 \\
\hline Propiedad por herencia & $-0,139$ & 0,135 & $0,066^{*}$ & 0,137 & $-0,581^{\star \star \star}$ & 0,098 & $-0,547^{\star \star \star}$ & 0,098 \\
\hline Alquilada & $1,408^{\star \star \star}$ & 0,067 & $1,374^{\star \star \star}$ & 0,075 & $0,354^{\star \star \star}$ & 0,046 & $0,237^{\star \star \star}$ & 0,049 \\
\hline Cedida & $1,064^{\star \star \star}$ & 0,136 & $1,141^{\star \star \star}$ & 0,136 & $-0,343^{\star \star}$ & 0,116 & $-0,339^{* *}$ & 0,116 \\
\hline Otra & $-0,086$ & 0,129 & 0,000 & 0,129 & $-0,754^{\star \star \star}$ & 0,097 & $-0,736^{\star \star \star}$ & 0,098 \\
\hline \multicolumn{9}{|l|}{ Lugar de nacimiento (ref. = cabecera del área) } \\
\hline Corona del área & & & $-0,884^{\star \star \star}$ & 0,076 & & & $0,418^{\star * *}$ & 0,066 \\
\hline Otra cabecera & & & $-0,393^{\star \star}$ & 0,114 & & & 0,011 & 0,066 \\
\hline Otra corona & & & $-0,629^{\star \star}$ & 0,193 & & & $-0,038$ & 0,118 \\
\hline No metropolitano & & & $-0,573^{\star \star \star}$ & 0,093 & & & $-0,054$ & 0,057 \\
\hline Extranjero & & & $-0,217^{\star \star}$ & 0,076 & & & $0,412^{\star \star \star}$ & 0,054 \\
\hline$\underline{\text { Constante }}$ & $-5,112^{\star \star \star}$ & 0,296 & $-4,692^{\star \star \star}$ & 0,299 & $-4,055^{\star \star \star}$ & 0,276 & $-4,101^{\star \star \star}$ & 0,273 \\
\hline$N$ & & 014.924 & & 14.924 & & 941.527 & & 941.527 \\
\hline Pseudo R² & & 0,15 & & 0,16 & & 0,20 & & 0,20 \\
\hline AIC & & 501.458 & & 96.423 & & 939.274 & & 936.318 \\
\hline BIC & & 107.640 & & 12.616 & & 234.227 & & 237.124 \\
\hline
\end{tabular}

${ }^{\star \star \star}=p<0,001 ;{ }^{* \star}=p<0,01 ;{ }^{*}=p<0,05$

Fuente: elaboración propia a partir del Censo de Población y Vivienda 2011. 
La centralización se dibuja como un movimiento también relacionado con la relocalización residencial tras trayectorias migratorias de largo recorrido, posiblemente asociadas a la búsqueda de oportunidades de empleo y mejora social, mientras que la explicación de lo segundo es algo más compleja y reafirma la centralización como un movimiento de retorno, pero no ya exclusivamente a la cabecera de origen, sino a un entorno similar. De este modo, tras trayectorias migratorias de cierto recorrido, los individuos tienden, a medio o largo plazo, a retornar a entornos centrales, aunque no sean exactamente los mismos en los que se criaron. Se pone así de manifiesto la gran importancia de las primeras etapas de la vida en la configuración de las percepciones sobre lo urbano y la vivienda, así como en la construcción de los vínculos afectivos de las personas con los tipos de espacios habitados.

En tercer lugar, cabe destacar que los coeficientes más negativos los presen$\tan$ aquellos que nacieron en entornos no centrales, especialmente los nacidos en la corona de la misma área. Este hecho refuerza la afirmación anterior sobre la importancia de las primeras etapas de la vida en la configuración de las preferencias residenciales, pero ahora en un sentido negativo. La ciudad central es una opción preferida cuando se conoce o se ha tenido algún contacto con ella, pero supone rechazo cuando se han experimentado en las primeras etapas de la vida entornos suburbanos o rurales.

En cuanto a la elección por las coronas, destaca en primer lugar que, a diferencia de la centralización, la mayoría de categorías no son significativas, concretamente, no existen diferencias estadísticamente significativas entre los nacidos en las cabeceras, en otras áreas y en lo no metropolitano, lo cual puede explicarse por el carácter más o menos generalizado de la elección suburbana, una forma de movilidad mayoritaria en las áreas metropolitanas españolas.

No obstante, esto no quiere decir que la experiencia residencial no tenga ningún efecto en la explicación de la elección suburbana. Dos categorías de la variable considerada aparecen como significativas y con signo positivo: los nacidos en la corona de la misma área y los nacidos en el extranjero. La significatividad de los primeros apunta a la idea de que la opción suburbana, más que un mero movimiento de ida de sujetos urbanitas que buscan la consecución de proyectos de vida familiares, es también un movimiento de retorno de antiguos residentes, un hecho hasta ahora relativamente ignorado. En cambio, la significatividad de los extranjeros muestra que la suburbanización es también una opción relevante tras migraciones de largo recorrido, algo que refuerza la hipótesis de que la población extranjera es más móvil.

Por último, se hace necesario comentar el efecto del resto de variables contempladas en los modelos, aunque no sea objeto central de este trabajo. Por una parte, la centralización se muestra como un movimiento diverso en lo que respecta a los cursos vitales, sin guardar relación con la edad, lo cual indica que presenta gran diversidad en estos términos. En cuanto a las formas de convivencia, se muestra especialmente vinculado a hogares no familiares, parejas sin hijos y otras familias distintas de la familia nuclear. Tiene gran importancia en su explicación la clase social, ya que es un movimiento muy 
relacionado con la movilidad de personas con estudios medios y, especialmente, superiores, y en el que pertenecer a categorías ocupacionales bajas supone un factor limitante. ${ }^{4}$ En términos de estilos de vida, el signo negativo del número de tareas y de todas las categorías del lugar de trabajo o estudios apuntan a que es un movimiento posiblemente muy vinculado a estilos de vida urbanos, basados en la externalización de tareas domésticas y la concentración de los espacios del habitar. No menos interesantes son los resultados relativos a la tenencia de la vivienda principal, que reflejan que, más allá de un claro predominio del alquiler, la centralización es a la par un movimiento relacionado con el acceso a vivienda cedida y heredada. Esto muestra un movimiento ciertamente alentado por la oportunidad que supone tener una vivienda en la ciudad, ya sea cedida por algún familiar o heredada, y se vincula así también en cierta medida al retorno a un entorno donde se tienen, o tenían, redes familiares.

Por su parte, la suburbanización parece, en términos de cursos vitales, un movimiento más propio de personas jóvenes que conviven principalmente en pareja sin hijos, quizás a la espera de expansión del hogar, pero en el que, aunque en menor medida que en la centralización, también tienen importancia los hogares no familiares y las otras familias. La escasa significatividad de las variables indicativas de la posición social revela un movimiento socialmente mixto, que no parece relacionarse de manera clara con ningún grupo social concreto. Si bien en el primer modelo realizado (modelo 1) aparecían como significativas con signo positivo las categorías de trabajadores de los servicios y empresarios, la importancia de estas se desvanecen al introducir el lugar de nacimiento (modelo 2), quizás porque esas categorías estaban reflejando el peso de determinados grupos, especialmente los extranjeros. En términos de estilos de vida, se muestra un movimiento claramente contrario a la centralización, caracterizado por una mayor asunción de tareas reproductivas y un mayor distanciamiento de los espacios de trabajo y estudio. En cuanto a la tenencia, aparte de la vivienda hipotecada (categoría de referencia), también destaca, aunque en menor medida que en la centralización, la vivienda en alquiler.

\subsection{Determinantes de los movimientos de ida y vuelta}

No obstante, más allá de estas vinculaciones señaladas entre la elección de entorno residencial y las características personales, la constatación de la importancia de la variable indicativa de la experiencia residencial hace plantearse si la explicación de la elección central o suburbana variará sustancialmente según la experiencia de los sujetos para con los entornos hacia los que se mueven. Con tal idea en mente, se desarrollan aquí dos modelos por cada elección a analizar.

4. Aunque pueda pensarse que la categoría empresarios se vincula a grupos sociales bien posicionados, en realidad es una categoría muy diversa en la que se concentran grandes empleadores, pero, sobre todo, dada la particularidad y debilidad del tejido productivo español, pequeños empresarios y autónomos que por sus condiciones de vida se asemejan más a la clase obrera que a las clases medias. 
El primero busca explicar los determinantes de los movimientos de retorno o vuelta, mientras que el segundo busca hacer lo mismo para los movimientos de ida. Dichos modelos muestran que, tanto para el caso de la centralización como para el de la suburbanización, los determinantes de los movimientos de ida y vuelta son claramente distintos.

Para el caso de la elección por la centralización (tabla 2), se observan unos movimientos de ida cuya explicación general se ajusta bastante a la explicación global de la centralización anteriormente expuesta, frente a unos movimientos de vuelta o retorno bastante más específicos. En términos de cursos vitales, no se aprecian grandes diferencias entre ambos. La edad no aparece como variable significativa en los movimientos de retorno, aunque sí lo hace la edad al cuadrado en los movimientos de ida, algo que podría ser indiciario de que los primeros se vinculan a grupos de edad más diversos. Por su parte, la forma de convivencia tampoco presenta grandes variaciones entre ambos, con un predominio claro de los hogares no familiares, las parejas sin hijos y las otras familias frente a los hogares con hijos. No obstante, los efectos de las distintas categorías son más marcados (presentan valores más altos) en el caso de los movimientos de ida respecto a los de vuelta, lo que puede apuntar a que el retorno se vincula a una miríada más amplia de opciones de convivencia. Pero sin duda, la mayor diferencia al respecto de los cursos vitales la apreciamos en la variable de estado civil. Esta variable nos informa de que el retorno a la cabecera está fuertemente vinculado al fin de proyectos de vida familiares en las coronas, sea por la muerte del cónyuge (viudedad), sea por ruptura marital (separación o divorcio), frente a unos movimientos de ida más diversos en los que también cobra importancia la categoría de solteros. Estos resultados parecen apuntar a que, si bien la elección por las cabeceras de aquellos que nunca han vivido en ellas puede responder a diferentes situaciones y momentos de los cursos vitales (emancipación, divorcio, etcétera), el retorno a las mismas es principalmente motivado por acontecimientos vitales negativos ligados al fracaso de un proyecto de vida familiar en las coronas. Una vuelta a un espacio conocido en el que refugiarse tras la disolución del hogar anterior.

$\mathrm{Al}$ respecto de la posición social, se notan mayores diferencias. En lo que concierne al nivel de estudios, se aprecia que tener estudios superiores es una condición importante para optar por las cabeceras, sin embargo, el efecto de los estudios es bastante mayor en el caso de los que se mueven hacia ellas por primera vez. Por su parte, la condición sociolaboral se muestra relevante para los movimientos de ida, para los cuales estar en categorías ocupacionales bajas supone un factor sustancialmente limitante de la elección. No ocurre así con los movimientos de retorno, los cuales no parecen guardar relación alguna con la condición social, y es solo un factor limitante para los mismos el hecho de estar parado. Esta menor importancia de la posición social en los movimientos de retorno apunta a la idea de que, cuando las personas han vivido previamente en la cabecera, la clase social deja de ser un factor tan relevante para moverse hacia la misma, mientras que sí que lo es cuando se va hacia ella por primera vez. La explicación de esto reside en el mayor capital localizado que pueden 
Tabla 2. Modelos para la explicación de la centralización según sea realizada por personas nacidas en las cabeceras hacia las que se mueven (vuelta) o no (ida)

\begin{tabular}{|c|c|c|c|c|}
\hline & \multicolumn{2}{|c|}{$\begin{array}{c}\text { Nacidos en cabecera } \\
\text { de la misma área }\end{array}$} & \multicolumn{2}{|c|}{$\begin{array}{c}\text { Nacidos en otros } \\
\text { entornos }\end{array}$} \\
\hline & $\mathrm{dy} / \mathrm{dx}$ & SE & $\mathrm{dy} / \mathrm{dx}$ & SE \\
\hline Edad & $-0,03 \%$ & 0,0003 & $0,03 \%$ & 0,0003 \\
\hline Edad al cuadrado & $0,00 \%$ & 0,0000 & $0,00 \%$ ** & 0,0000 \\
\hline \multicolumn{5}{|l|}{ Sexo (ref. = mujer) } \\
\hline Hombre & $0,15 \%$ & 0,0012 & $0,42 \%$ *夫 & 0,0014 \\
\hline \multicolumn{5}{|l|}{ Estado civil (ref. = casado) } \\
\hline Soltero & $0,25 \%$ & 0,0017 & 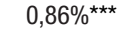 & 0,0018 \\
\hline Viudo & $0,81 \%$ * & 0,0038 & 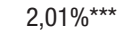 & 0,0030 \\
\hline Separado o divorciado & 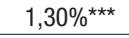 & 0,0020 & 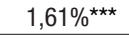 & 0,0021 \\
\hline \multicolumn{5}{|l|}{ Forma de convivencia (ref. = unipersonal) } \\
\hline No familiar & 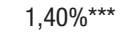 & 0,0029 & 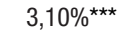 & 0,0030 \\
\hline Monop. hijos menores & 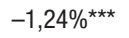 & 0,0029 & $-1,19 \%$ ** & 0,0035 \\
\hline Monop. hijos mayores & $-0,38 \%$ & 0,0027 & $-0,20 \%$ & 0,0036 \\
\hline Pareja sin hijos & $0,42 \%$ * & 0,0019 & 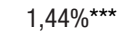 & 0,0024 \\
\hline Pareja con hijos menores & 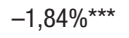 & 0,0023 & 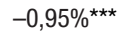 & 0,0025 \\
\hline Pareja con hijos mayores & 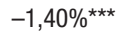 & 0,0026 & $-1,95 \%$ *** & 0,0041 \\
\hline Otras familias & $0,52 \%$ * & 0,0021 & 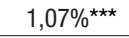 & 0,0023 \\
\hline \multicolumn{5}{|l|}{ Nivel de estudios (ref. = primarios o menos) } \\
\hline Secundarios & $0,05 \%$ & 0,0022 & $-0,14 \%$ & 0,0021 \\
\hline Bachiller o FP & $0,38 \%$ & 0,0021 & $0,43 \%$ * & 0,0021 \\
\hline Superiores & 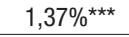 & 0,0023 & $1,53 \%$ ** & 0,0022 \\
\hline \multicolumn{5}{|l|}{ Condición sociolaboral (ref. = administrativos) } \\
\hline Profesionales & $-0,09 \%$ & 0,0017 & $0,37 \%$ & 0,0021 \\
\hline Servicios & $-0,05 \%$ & 0,0021 & $0,42 \%$ & 0,0022 \\
\hline Operarios & $-0,36 \%$ & 0,0022 & 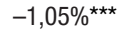 & 0,0025 \\
\hline Empresarios & $-0,46 \%$ & 0,0025 & $-0,68 \%$ * & 0,0029 \\
\hline Otros ocupados & $-0,85 \%$ & 0,0044 & $-0,42 \%$ & 0,0039 \\
\hline Parados & $-0,62 \%$ ** & 0,0023 & $-0,06 \%$ & 0,0023 \\
\hline Inactivos & $-0,18 \%$ & 0,0049 & $-0,82 \%$ & 0,0050 \\
\hline N. ${ }^{0}$ de tareas domésticas que realiza & $-0,17 \%^{*}$ & 0,0007 & $-0,31 \%$ *** & 0,0009 \\
\hline \multicolumn{5}{|c|}{ Lugar de trabajo o estudios (ref. = mismo municipio) } \\
\hline Otro municipio del área & 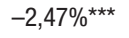 & 0,0018 & 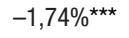 & 0,0019 \\
\hline Fuera del área & 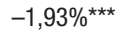 & 0,0037 & 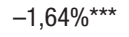 & 0,0031 \\
\hline Varios municipios & 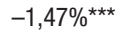 & 0,0027 & $-0,87 \%^{*}$ & 0,0040 \\
\hline Mismo domicilio & 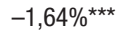 & 0,0026 & $-0,67 \%$ ** & 0,0025 \\
\hline No estudia ni trabaja & 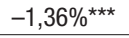 & 0,0016 & 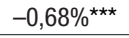 & 0,0015 \\
\hline \multicolumn{5}{|c|}{ Tenencia de la vivienda principal (ref. = propiedad hipotecada) } \\
\hline Propiedad totalmente pagada por compra & $-0,02 \%$ & 0,0017 & $-0,90 \%$ *** & 0,0022 \\
\hline Propiedad por herencia & $0,86 \%$ ** & 0,0026 & $-1,14 \%$ ** & 0,0037 \\
\hline Alquilada & $2,53 \%$ *** & 0,0016 & $2,50 \%$ *** & 0,0018 \\
\hline Cedida & 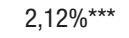 & 0,0029 & 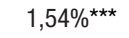 & 0,0036 \\
\hline Otra & $0,14 \%$ & 0,0029 & $-0,37 \%$ & 0,0032 \\
\hline $\mathrm{N}$ & & 289.478 & & 725.446 \\
\hline Pseudo R² & & 0,16 & & 0,16 \\
\hline
\end{tabular}

${ }^{\star * *}=\mathrm{p}<0,001 ;{ }^{* *}=\mathrm{p}<0,01 ;{ }^{*}=\mathrm{p}<0,05$

Fuente: elaboración propia a partir del Censo de Población y Vivienda 2011. 
acumular las personas que retornan (bien sea un capital físico, como puede ser una vivienda, bien sea más abstracto, como redes sociales o conocimientos sobre los mercados de trabajo y vivienda), el cual puede suplir la (des)ventaja comparativa que representa la pertenencia a determinados estratos sociales.

Precisamente, ese mayor capital cultural o conocimiento sobre el mercado local de trabajo es el que esté detrás de las variaciones observadas respecto a la variable de lugar de trabajo o estudios. Como puede apreciarse, si bien tanto en los movimientos de ida como en los de vuelta todas las categorías presentan signo negativo respecto a trabajar en el mismo municipio cabecera (categoría de referencia), este efecto es mucho más marcado en los movimientos de retorno. Este hecho puede explicarse por el mayor conocimiento del mercado local de trabajo que tienen los retornados, así como posiblemente las mayores redes de contactos de que disponen debido a su experiencia residencial, algo que les permite, en mayor medida que a los que van por primera vez, localizar su lugar de trabajo y estudios en el seno del mismo municipio.

Por último, no menos relevantes se muestran los resultados que arroja la variable de tenencia de la vivienda principal. Si bien la vivienda en alquiler y la vivienda cedida parecen ser las opciones preferidas por ambos grupos, en los movimientos de retorno tiene un efecto positivo vivir en una vivienda heredada. Este hecho indica que el retorno a la cabecera de origen se vincula no solo al alquiler o al acceso a una vivienda cedida, sino también a la propiedad de una vivienda legada, lo cual dibuja unos movimientos de retorno a las cabeceras ciertamente motivados por la posibilidad que supone poseer un capital físico, como es la vivienda, en la cabecera de origen.

Para el caso de la elección por la suburbanización (tabla 3), también encontramos diferencias en los determinantes de los movimientos de retorno respecto a los de ida. En términos de cursos vitales, se aprecian diferencias relevantes. Respecto a la edad, se observa que, aunque es significativa y con signo negativo en ambos movimientos, su efecto es mayor en el caso de los nacidos en otros entornos, lo que indica que los retornados son algo mayores que los que van por primera vez a lo suburbano. Mayores diferencias encontramos al observar el estado civil y la forma de convivencia. Estas variables perfilan unos movimientos de ida ciertamente diversos, vinculados a la movilidad de solteros, viudos, divorciados y separados, así como a una amplia miríada de formas de convivencia, principalmente parejas sin hijos, pero también hogares no familiares y otras familias. Sin embargo, los movimientos de retorno a lo suburbano parecen mucho más específicos a este respecto, y se dibujan como unos movimientos fuerte y exclusivamente vinculados a la condición de estar separado o divorciado y al hecho de no tener hijos o vivir en otros hogares familiares. Esto perfila un retorno a lo suburbano ciertamente similar al retorno a las cabeceras, ambos motivados por el fracaso del proyecto de vida familiar y la consiguiente búsqueda de refugio en el entorno de origen para rehacer la vida.

También se aprecian diferencias relevantes en lo referente a la posición social. Por un lado, los movimientos de retorno parecen no guardar ninguna relación clara con ninguna de las dos variables consideradas (nivel de estudios 
Tabla 3. Modelos para la explicación de la suburbanización según sea realizada por personas nacidas en las coronas hacia las que se mueven (vuelta) o no (ida)

\begin{tabular}{|c|c|c|c|c|}
\hline & \multicolumn{2}{|c|}{$\begin{array}{l}\text { Nacidos en corona } \\
\text { de la misma área }\end{array}$} & \multicolumn{2}{|c|}{$\begin{array}{l}\text { Nacidos en otros } \\
\text { entornos }\end{array}$} \\
\hline & $\mathrm{dy} / \mathrm{dx}$ & SE & $\mathrm{dy} / \mathrm{dx}$ & SE \\
\hline Edad & $-0,06 \%$ ** & 0,0002 & $-0,10 \%$ *** & 0,0001 \\
\hline Edad al cuadrado & $0,00 \%$ & 0,0000 & $0,00 \%{ }^{\star \star \star}$ & 0,0000 \\
\hline \multicolumn{5}{|l|}{ Sexo (ref. = mujer) } \\
\hline Hombre & $-0,15 \%$ & 0,0012 & $-0,01 \%$ & 0,0005 \\
\hline \multicolumn{5}{|l|}{ Estado civil (ref. = casado) } \\
\hline Soltero & $-0,01 \%$ & 0,0017 & $0,32 \%{ }^{\star \star \star}$ & 0,0009 \\
\hline Viudo & $0,19 \%$ & 0,0034 & $0,92 \%{ }^{\star \star \star}$ & 0,0014 \\
\hline Separado o divorciado & $0,76 \%$ *** & 0,0019 & $1,06 \%{ }^{\star \star \star}$ & 0,0009 \\
\hline \multicolumn{5}{|l|}{ Forma de convivencia (ref. $=$ unipersonal) } \\
\hline No familiar & $0,13 \%$ & 0,0038 & $0,52 \%$ ** & 0,0016 \\
\hline Monop. hijos menores & $-0,64 \%$ * & 0,0029 & $-1,31 \%$ *** & 0,0015 \\
\hline Monop. hijos mayores & $-0,09 \%$ & 0,0026 & $-1,02 \%$ *** & 0,0016 \\
\hline Pareja sin hijos & $0,23 \%$ & 0,0020 & $1,10 \%{ }^{\star \star \star}$ & 0,0009 \\
\hline Pareja con hijos menores & $-0,84 \%$ *** & 0,0021 & $-0,45 \%$ *** & 0,0010 \\
\hline Pareja con hijos mayores & $-0,32 \%$ & 0,0025 & $-1,08 \%$ *** & 0,0015 \\
\hline Otras familias & $0,56 \%$ ** & 0,0020 & $0,44 \%{ }^{\star \star \star}$ & 0,0009 \\
\hline \multicolumn{5}{|l|}{ Nivel de estudios (ref. = primarios o menos) } \\
\hline Secundarios & $-0,03 \%$ & 0,0016 & $0,02 \%$ & 0,0011 \\
\hline Bachiller o FP & $-0,14 \%$ & 0,0018 & $-0,01 \%$ & 0,0010 \\
\hline Superiores & $-0,30 \%$ & 0,0022 & $-0,14 \%$ & 0,0011 \\
\hline \multicolumn{5}{|l|}{ Condición sociolaboral (ref. = administrativos) } \\
\hline Profesionales & $0,13 \%$ & 0,0019 & $-0,15 \%{ }^{*}$ & 0,0007 \\
\hline Servicios & $0,19 \%$ & 0,0020 & $0,17 \%$ * & 0,0008 \\
\hline Operarios & $-0,09 \%$ & 0,0021 & $-0,11 \%$ & 0,0010 \\
\hline Empresarios & $0,36 \%$ & 0,0024 & $0,24 \%$ * & 0,0012 \\
\hline Otros ocupados & $-1,08 \%$ * & 0,0054 & $-0,69 \%$ *** & 0,0017 \\
\hline Parados & $-0,24 \%$ & 0,0021 & 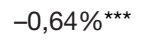 & 0,0010 \\
\hline Inactivos & $0,43 \%$ & 0,0048 & $-0,14 \%$ & 0,0021 \\
\hline N. ${ }^{\circ}$ de tareas domésticas que realiza & $-0,05 \%$ & 0,0008 & $0,12 \%{ }^{\star \star \star}$ & 0,0003 \\
\hline \multicolumn{5}{|c|}{ Lugar de trabajo o estudios (ref. = mismo municipio) } \\
\hline Otro municipio del área & $1,84 \%$ *** & 0,0020 & $3,89 \%$ *** & 0,0011 \\
\hline Fuera del área & $0,52 \%$ & 0,0038 & $1,52 \%$ *** & 0,0017 \\
\hline Varios municipios & $0,96 \%$ *** & 0,0027 & $1,96 \%$ *** & 0,0014 \\
\hline Mismo domicilio & $0,72 \%$ ** & 0,0027 & $1,82 \%$ *** & 0,0012 \\
\hline No estudia ni trabaja & 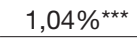 & 0,0019 & 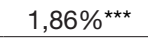 & 0,0011 \\
\hline \multicolumn{5}{|l|}{$\begin{array}{l}\text { Tenencia de la vivienda principal } \\
\text { (ref. = propiedad hipotecada) }\end{array}$} \\
\hline Propiedad totalmente pagada por compra & $-0,68 \%$ *** & 0,0016 & 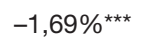 & 0,0008 \\
\hline Propiedad por herencia & $0,18 \%$ & 0,0020 & 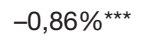 & 0,0014 \\
\hline Alquilada & $0,46 \%^{* \star}$ & 0,0015 & $0,43 \% \%^{\star \star \star}$ & 0,0006 \\
\hline Cedida & $-0,65 \%$ & 0,0034 & $-0,39 \%$ ** & 0,0015 \\
\hline Otra & $-0,51 \%$ & 0,0027 & 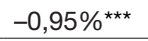 & 0,0013 \\
\hline $\mathrm{N}$ & & 50.315 & & 891.212 \\
\hline Pseudo R² & & 0,15 & & 0,21 \\
\hline
\end{tabular}

Fuente: elaboración propia a partir del Censo de Población y Vivienda 2011. 
y condición sociolaboral). Al igual que ocurría con el retorno a las cabeceras, el retorno a lo suburbano no está motivado ni restringido por las constricciones sociales, posiblemente porque se disponga de otros recursos localizados que puedan sortear las restricciones que impone la posición social, o simplemente porque se trate de movimientos socialmente mixtos, motivados exclusivamente por eventos de los cursos vitales. Sin embargo, por otro lado, la posición social sí que parece especialmente relevante para los movimientos de ida, aunque en un sentido muy diferente a los movimientos de ida hacia las cabeceras. Al contrario que la centralización, la suburbanización de aquellos que no tienen experiencia en el entorno suburbano se vincula a categorías ocupacionales bajas y población inactiva, pero no a parados. La explicación de la vinculación a categorías ocupacionales bajas es compleja, y quizás responda a que la suburbanización se configura, en parte, como un movimiento que realizan los sectores populares en la búsqueda de unas viviendas a precios aceptables, empujados por la saturación y la tendencia alcista de unas cabeceras salpicadas por crecientes procesos de gentrificación en un contexto de crisis económica. Por su parte, la presencia de inactivos puede indicar dos cosas: por un lado, que la ida a lo suburbano sea en parte un movimiento de retiro ante el fin de la vida activa; por otro, puede estar reflejando el carácter más convencional del reparto de tareas domésticas de la población que opta por este movimiento, con una mayor presencia de amas de casa, hipótesis que cobra fuerza al observar el variable número de tareas domésticas que la persona realiza, significativa y con signo positivo.

Respecto a la variable de lugar de trabajo o estudio, se aprecia que el clásico estilo de vida suburbano tendente a la dispersión de los espacios del habitar está mucho más marcado en el caso de los movimientos de ida, pero no así en los de retorno, en los que el efecto de las categorías de esta variable no es tan fuerte. Detrás de la explicación de estas diferencias, quizás esté también el mayor conocimiento y las redes de contacto que tienen los retornados, las cuales les posibilitan encontrar un lugar de trabajo o estudios más cercano a su domicilio, al igual que ocurría en el caso de la centralización.

Por último, cabe destacar las variaciones en la tenencia de la vivienda principal. Si bien los movimientos de ida a lo suburbano parecen claramente vinculados al acceso a vivienda en propiedad hipotecada y en alquiler, las opciones de los retornados parecen más diversas y no presentan diferencias significativas entre el acceso a la propiedad con hipoteca y la vivienda heredada y cedida.

\section{Conclusiones}

Siguiendo la línea iniciada por algunas aportaciones anteriores (Blaauboer, 2011; Feijten et al., 2008), el presente trabajo profundiza precisamente en la relevancia de la experiencia residencial y responde a dos cuestiones fundamentales para entender la elección de entorno: ¡cómo la experiencia residencial previa de los sujetos con los distintos entornos influye en la elección por los mismos? y, algo hasta ahora inexplorado, jexisten diferencias en los determi- 
nantes individuales de elección de entorno residencial según dicha experiencia previa?

Respecto a la primera pregunta, nuestro estudio confirma que la experiencia residencial es un factor clave para entender los procesos de elección de entorno, tanto por los centrales como los suburbanos. La elección por las cabeceras se encuentra muy marcada por la experiencia previa con las mismas, sea con la misma cabecera hacia la que el sujeto se muda o sea con otra. Esta importancia también se manifiesta de manera negativa, ya que parece que aquellos que han nacido en entornos suburbanos o rurales tienen cierto rechazo a mudarse hacia las cabeceras. Los entornos centrales atraen a aquellos que los han experimentado directamente. En cuanto a la opción suburbana, el efecto de la experiencia residencial en ella parece ciertamente más débil que en la opción central, aunque el hecho de haber nacido en la corona hacia la que se mueve se muestra como un factor relativamente importante de la elección.

No obstante, la principal aportación que hace este trabajo es respecto a la segunda pregunta, al demostrar que los determinantes de la elección residencial son ciertamente diferentes según si esta elección se enmarca dentro de una trayectoria de ida o vuelta al entorno en cuestión. De un lado, vemos grandes similitudes en las trayectorias de retorno, independientemente del entorno de destino. Se aprecia como el retorno se vincula principalmente al fin o al fracaso del proyecto de vida familiar, en que el divorcio o la separación son su principal desencadenante. Los movimientos de vuelta se configuran así como una suerte de vuelta a un lugar de origen en el que posiblemente se conserven redes de apoyo y cierto conocimiento del mercado laboral, algo que se deduce de la mayor capacidad de los retornados para localizar el trabajo en el mismo municipio de residencia, así como ciertos recursos materiales y sociales, lo cual se aprecia por la relevancia que tienen en estos movimientos las viviendas heredadas y cedidas y por la escasa importancia que tienen para los retornados las restricciones relativas a la posición social. De otro lado, los movimientos de ida se muestran más heterogéneos, vinculados a una miríada de eventos vitales y posiciones sociales, y existen diferencias relevantes en los mismos según el entorno hacia el que los sujetos se muevan. Así, los movimientos de ida hacia las cabeceras se perfilan como movimientos menos familiares y propios de clases medias con altos niveles formativos. Por su parte, los movimientos de ida hacia las coronas son heterogéneos en términos de cursos vitales, aunque se vinculan en mayor medida a sujetos jóvenes y parejas sin hijos. Socialmente, es un movimiento propio de sectores populares, posiblemente empujados a las coronas metropolitanas por los elevados precios de las viviendas de las cabeceras.

La constatación de la importancia de la experiencia residencial en la elección por la centralización y la suburbanización pone sobre la mesa la necesidad de analizar la elección residencial en un contexto biográfico más amplio. Explicar y comprender el comportamiento residencial supone ir más allá de las motivaciones y los acontecimientos vitales inmediatos de los actores a los que tradicionalmente se ha recurrido, ya que requiere considerar las trayectorias 
vitales y residenciales de largo recorrido en la medida en que estas suponen variaciones relevantes del comportamiento residencial en general y de la elección de entorno en particular. Conceptos propios de la sociología de la acción como el de imaginario, capital o disposición son por tanto muy necesarios para tratar de explicar y comprender las decisiones de movilidad de los actores. Entender lo urbano como un campo social donde los actores toman decisiones (y compiten por tomar posiciones) empleando sus recursos (o capitales) disponibles y guiados por sus imaginarios puede ser un buen punto de partida para guiar la investigación futura. Las implicaciones de considerar estas herramientas conceptuales de la sociología de la acción para analizar el comportamiento residencial suponen la necesidad de desarrollar nuevas estrategias metodológicas. Desde una óptica cuantitativa, nos impone la necesidad de tener en consideración la construcción de modelos que, de un modo u otro, introduzcan variables que permitan operacionalizar los componentes más concretos de la experiencia residencial que este trabajo no trata directamente por falta de datos — redes sociales, conocimiento de los entornos, propiedades y capital localizado, imaginarios sobre los entornos, etcétera—, así como la necesidad de reconstruir trayectorias concretas, cuando la disponibilidad de datos longitudinales para España lo permita. Desde la investigación cualitativa, supone la necesidad de profundizar en los procesos de construcción subjetiva de lo residencial, así como analizar el comportamiento de los actores en un sentido histórico, a través de las posibilidades que la técnica de las historias de vida ofrece. Por tanto, más allá de la aportación coyuntural de este trabajo, queda toda una línea de indagación empírica, pero también teórica, que tiene como fin profundizar en la compleja relación entre elección y experiencia residencial.

\section{Referencias bibliográficas}

Æro, T. (2006). «Residential Choice from a Lifestyle Perspective». Housing, Theory and Society, 23 (2), 109-130. $<$ https://doi.org/10.1080/14036090600773139>

AlBerich, J. (2010). «La metropolitanització del territori català: una anàlisi a partir dels espais de vida de la poblacióm. Treballs de la Societat Catalana de Geografia, 69, 39-65.

Aragonés Tapia, J. I. y Amérigo Cuervo-Arango, M. (1987). «Movilidad residencial en la ciudad. Factores determinantes y consecuencias». Estudios sobre Consumo, $11(7), 122-135$.

Atrinson, R. y Bridge, G. (2005). Gentrification in a global context. The new urban colonialism. Londres: Routledge.

Bachelard, G. (1957). La poética del espacio. Madrid: Fondo de Cultura Económica.

Bailey, A. J.; Blake, M. K. y Cooke, T. J. (2004). «Migration, care and the linked lives of dual-earner households». Environment and Planning A, 36, 1.617-1.632. $<$ https://doi.org/10.1068/a36198>

Bayoh, I.; IrWin, E. G. y HaAB, T. (2006). «Determinants of residential location choice: How important are local public goods in attracting homeowners to central city locations?». Journal of Regional Science, 46 (1), 97-120.

<https://doi.org/10.1111/j.0022-4146.2006.00434.x> 
BlaAuboer, M. (2011). «The Impact of Childhood Experiences and Family Members Outside the Household on Residential Environment Choices». Urban Studies, 48 (8), 1.635-1.650. <https://doi.org/10.1177/0042098010377473>

Booi, H. y Boterman, W. R. (2020). «Changing patterns in residential preferences for urban or suburban living of city dwellers». Journal of Housing and the Built Environment, 35, 93-123. <https://doi.org/10.1007/s10901-019-09678-8>

Boterman, W. R.; Karsten, L. y Musterd, S. (2010). «Gentrifiers Settling Down? Patterns and Trends of Residential Location of Middle-Class Families in Amsterdam». Housing Studies, 25 (5), 693-714. <https://doi.org/10.1080/02673037.2010.483586>

Buzar, S.; Hall, R. y Ogden, P. E. (2007). «Beyond gentrification: The demographic reurbanisation of Bologna». Environment and Planning A, 39 (1), 64-85. $<$ https://doi.org/10.1068/a39109>

CAssarino, J.-P. (2004). «Theorising return migration: a revisited conceptual approach to return migrants». Mediterranean Programme, 02. San Domenico di Fiesole.

Castells, M. (1976). La cuestión urbana. Madrid: Siglo XXI.

Caufield, J. (1993). City form and everyday life: Toronto's gentrification and critical social practice. Toronto: Toronto University Press.

Clapham, D. (2002). «Housing Pathways: A Post Modern Analytical Framework». Housing Theory and Society Theory and Society, 19 (2), 57-68. <https://doi.org/10.1080/140360902760385565>

Clark, W. A. V.; Duque-Calvache, R. y Palomares-Linares, I. (2015). «Place Attachment and the Decision to Stay in the Neighbourhood». Population Space and Place. $<$ https://doi.org/10.1002/psp.2001>

Conde, F. (1999). Urbanismo y ciudad en la aglomeración de Granada. Culturas e identidades urbanas. Sevilla: Empresa Pública del Suelo-Junta de Andalucía.

Cooke, T. J. y Denton, C. (2015). «The suburbanization of poverty? An alternative perspective». Urban Geography, 36 (2), 300-313. <https://doi.org/10.1080/02723638.2014.973224>

Cosacov, N.; Virgilio, M. M. di y Najman, M. (2018). «Movilidad residencial de sectores medios y populares: la ciudad de Buenos Aires como punto de llegada». Cadernos Metrópole, 20 (41), 99-121. <https://doi.org/10.1590/2236-9996.2018-4105>

DA VANZo, J. (1981). «Repeat migration, information costs, and location-specific capital». Population and Environment, 4 (1).

Dawkins, C. J. (2006). "Are social networks the ties that bind families to neighborhoods?». Housing Studies, 21 (6), 867-881. <https://doi.org/10.1080/02673030600917776>

Dejong, G. F. y Gardner, R. W. (1981). Migration Decision-Making. Nueva York: Pergamon Press.

Deurloo, M. C.; Clark, W. A. V. y Dieleman, F. M. (1990). «Choice of Residential Environment in the Randstad». Urban Studies, 27 (3), 335-351. <https://doi.org/10.1080/00420989020080311>

Duque-Calvache, R. (2015). Áreas metropolitanas andaluzas. La movilidad residencial y su relación con la vivienda. Sevilla: Consejería de Fomento de la Junta de Andalucía. 
- (2016). Procesos de gentrificación en cascos antiguos: el Albaicin de Granada. Madrid: Centro de Investigaciones Sociológicas.

Escobar, M.; Fernández, E. y Bernardi, F. (2009). Análisis de datos con Stata. Madrid: Centro de Investigaciones Sociológicas.

Feijten, P. y Ham, M. van (2007). «Residential mobility and migration of the divorced and separated». Demographic Research, 17, 623-654.

<https://doi.org/10.4054/DemRes.2007.17.21>

Feijten, P.; Hooimeijer, P. y Mulder, C. H. (2008). «Residential Experience and Residential Environment Choice over the Life-course». Urban Studies, 45 (1), 141-162. <https://doi.org/10.1177/0042098007085105>

Feldman, R. (1990). «Settlement-Identity: Psychological Bonds with Home Places in a Mobile Society». Environment and Behavior, 22 (2), 56-79. <https://doi.org/10.1177/0013916590222002>

- (1996). "Constancy and change in attachments to types of settlements». Environment and Behavior, 28 (4), 419-445. <https://doi.org/10.1177/0013916596284001>

Feria, J. M. y Martínez, L. (2016). «La definición y delimitación del sistema metropolitano español. Permanencias y cambios entre 2001 y 2011». Ciudad y Territorio. Estudios Territoriales, 48 (187).

Fielding, A. (1992). «Migration and Social Mobility: South-East England as an Escalator Region». Regional Studies, 26, 1-15. $<$ https://doi.org/10.1080/00343409212331346741>

Frey, W. H. (1985). «Mover Destination Selectivity and the Changing Suburbanization of Metropolitan Whites and Blacks». Demography, 22 (2), 223-243. $<$ https://doi.org/10.2307/2061179>

Frey, W. H. y Kobrin, F. E. (1982). "Changing Families and Changing Mobility: Their Impact on the Central City». Demography, 19 (3), 261-277. $<$ https://doi.org/10.2307/2060970>

Gober, P. y Behr, M. (1982). «Central Cities and Suburbs as Distinct Place Types: Myth or Fact?». Economic Geography, 58 (4), 371-385. <https://doi.org/10.2307/143461>

KintreA, K. (2007). «Housing aspirations and obsolescence: understanding the relationship». Journal of Housing and the Built Environment, 22 (4), 321-338. <https://doi.org/10.1007/s10901-007-9087-4>

Lees, L.; Slater, T. y Wyly, E. (2013). Gentrification. Nueva York: Routledge.

LeY, D. (1996). The New Middle Class and the Remaking of the Central City. Toronto: Oxford Geographical and Environmental Studies Series.

López-Gay, A. y Recaño, J. (2008). «La renovación socio-demográfica de un centro urbano maduro: perfiles migratorios y filtros residenciales en la ciudad de Barcelona». Scripta Nova, 12 (126). <https://revistes.ub.edu/index.php/ScriptaNova/ article/view/1554/1530>.

Lupi, T. y Musterd, S. (2016). "The Suburban "Community Question"». Urban Studies, 43 (4), 801-817. <https://doi.org/10.1080/00420980600597723>

Mahmud, S. A.; Ahmad, A. S. y Abdullah, A. M. (2012). "Lifestyle Orientation and the Residential Environment: An Exploratory Review». Procedia-Social and Behavioral Sciences, 49, 304-309. <https://doi.org/10.1016/j.sbspro.2012.07.028> 
Marois, G. y BÉLANGer, A. (2013). «De la banlieue à la ville centre: déterminants de la mobilité résidentielle des banlieusards de Montréal». Canadian Journal of Urban Research, 22 (2), 45-68.

Martín-Criado, E. (2013). «Cabilia: la problemática génesis del concepto de habitus». Revista Mexicana de Sociología, 1 (34), 125-151.

Michielin, F. y Mulder, C. H. (2008). «Family events and the residential mobility of couples». Environment and Planning A, 40 (11), 2.770-2.790. $<$ https://doi.org/10.1068/a39374>

Mieszkowski, P. y Mills, E. S. (1993). «The Causes of Metropolitan Suburbanization». The Journal of Economic Perspectives, 7 (3), 135-147. <https://doi.org/10.1257/jep.7.3.135>

Miller, L. J. (1995). «Family Togetherness and the Suburban Ideal». Sociological Forum, 10 (3), 393-418. <https://doi.org/10.1007/bf02095828>

Mulder, C. H. y Cooke, T. J. (2009). «Family ties and residential locations». Population, Space and Place, 15 (4), 299-304. <https://doi.org/10.1002/psp.556>

Mulder, C. H. y Hooimeijer, P. (1999). "Residential Relocations in the Life Course». En: Wissen, L. J. G. van y Dykstra, P. A. (eds.). Population Issues. The Plenum Series on Demographic Methods and Population Analysis. Dordrecht: Springer, 159-186. <https://doi.org/10.1007/978-94-011-4389-9_6>

Nelson, K. P. y Edwards, J. G. (1993). «Intra-urban mobility and location choice in the 1980s». En: Kingsley, G. T. y Turner, M. A. (eds.). Housing markets and residential mobility. Washington, DC: Urban Institute Press, 53-95.

Otero-Enríquez, R. (2017). "Sociología e historia de la ciudad desconcentrada». Madrid: Centro de Investigaciones Sociológicas.

Pablos, J. C. de y Sánchez-Tovar, L. (2003). "Estilos de vida y revitalización del espacio urbano". Papers. Revista de Sociologia, 71, 11-31. <https://doi.org/10.5565/rev/papers/v71n0.1148>

Pino-Artacho, J. A. del (2013). Estructuras residenciales y movilidad: más allá de la segunda residencia. Madrid: Centro de Investigaciones Sociológicas.

Pisman, A.; Allaert, G. y Lombaerde, P. (2011). "Urban and suburban lifestyles and residential preferences in a highly urbanized society experiences from a case study in Ghent (Flanders, Belgium)». Belgeo (1-2), 89-104. $<$ https://doi.org/10.4000/belgeo.6394>

Rossi, P. (1955). Why families move: A study in the social psychology of urban residential mobility. Nueva York: Free Press.

Schnell, I. y Gracier, I. (1993). "Causes of In-migration to Tel-Aviv Inner City Causes of In-migration to Tel-Aviv Inner City». Urban Studies, 30 (7). $<$ https://doi.org/10.1080/00420989320081121>

Shin, E. J. (2012). An Empirical Study of Urban/Suburban Residential Location Choice in the Seattle Metropolitan Area. Tesis de máster. Department of Design and Urban Planning, University of Washington, Washington DC.

Stovel, K. y Bolan, M. (2004). «Residential Trajectories». Sociological Methods and Research, 32 (4), 559-598. <https://doi.org/10.1177/0049124103262683>

Susino, J. (2003). Movilidad residencial: procesos demográficos, estrategias familiares y estructura social. Tesis doctoral inédita. Departamento de Sociología, Universidad de Granada, Granada. 
Susino, J. y Duque-Calvache, R. (2012). «Veinte años de suburbanización en España, 1981-2001: el perfil de sus protagonistas». Documents d'Anàlisi Geográfica, 59 (2), 265-290. <https://doi.org/10.5565/rev/dag.31>

Torrado, J. M. (2018). «¿Seleccionan las ciudades a su población? Tendencias de selectividad residencial en las cabeceras metropolitanas andaluzas». Cuadernos Geográficos, 57 (2), 1-26. <http://dx.doi.org/10.30827/cuadgeo.v57i2.5935>

- (2020). Flujos espaciales y dinámicas residenciales de centralización en las áreas metropolitanas españolas. Tesis doctoral inédita. Departamento de Sociología, Universidad de Granada, Granada.

Turcotte, M. y VéZInA, M. (2010). «Migration entre municipalité centrale et municipalités avoisinantes à Toronto, Montréal et Vancouver». Tendances Sociales Canadiennes (11), 008- X.

Ullá́n De la Rosa, F. J. (2014). Sociología urbana: de Marx y Engels a los teóricos posmodernos. Madrid: Centro de Investigaciones Sociológicas.

VIRY, G. (2012). «Residential mobility and the spatial dispersion of personal networks: Effects on social support». Social Networks, 34 (1), 59-72. $<$ https://doi.org/10.1016/j.socnet.2011.07.003>

Williams, R. (2012). «Using the margins command to estimate and interpret adjusted predictions and marginal effects». Stata Journal, 12 (2), 308-331. <https://doi.org/10.1177/1536867x1201200209> 
